\section{Otuneye AT \\ Ahmed PA \\ Abdulkarim AA \\ Aluko OO \\ Shatima DR}

DOI:http://dx.doi.org/10.4314/njp.v44i3.1

Accepted: 9th February 2017

Ahmed PA ( $\mathbf{\nabla}$ )

Otuneye AT, Shatima DR

Department of Paediatrics,

National hospital Abuja- Nigeria

Email: ahmedpatience@yahoo.com

Abdulkarim AA

Department of Paediatrics,

University of Ilorin Teaching

Hospital, Ilorin- Nigeria

Aluko OO

Department of Community

Medicine, Obafemi Awolowo

University, Ile-Ife- Nigeria

\title{
CC-BY Relationship between dietary habits and nutritional status among adolescents in Abuja municipal area council of Nigeria
}

\begin{abstract}
Background: Dietary intake assessment is essential to understanding the nutritional status. Healthy eating pattern promotes optimal health, growth and intellectual development and prevents diseases, while poor dietary eating choices may cause malnutrition.
\end{abstract}

Aims: To determine the dietary eating patterns and nutritional status among adolescents in secondary schools within Abuja Municipal area council (AMAC).

Subjects and Methods: crosssectional among adolescents, 10 19years in secondary schools within AMAC, Nigeria. Using a multistage stratified sampling technique, four urban and four rural schools, 1550 students, were enrolled. Subject's bio data, dietary habits and knowledge of nutrition and general physical examination were obtained. Dietary assessment included intake of main meals (breakfast, lunch and dinner), skipping meals; methods used to control weight in the previous 30days; knowledge and preference of a balanced diet and food choices. Subject's height and weight and Body Mass Index (BMI) were determined using the 2007 WHO charts. Data was analyzed using SPSS version 17 statistical package and $\mathrm{p}$ value less than 0.05 was significant.

Results: 1550 students were recruited, males $688(44.4 \%)$ and females 862 (55.6\%); mean age $14.43 \pm 1.94$ years. Of the 780 urban adolescents, $502(64.4 \%)$ were of upper class and $68(8.7 \%)$ lower class; and of the 770 $(49.7 \%)$ rural, 206 (26.8\%) and
$232(30.1 \%)$ belong to upper and lower class respectively, $\mathrm{p}=.000$. Stunting $174(11.2 \%)$ and overweight $195(12.6 \%)$ were the major forms of malnutrition recorded. Food preferences was based mainly on good taste in 546 $(35.2 \%)$, balanced diet 530 $(34.2 \%)$; and 539 (34.8\%) had good nutritional knowledge of a balanced diet. Five hundred and forty six (35.2\%) admitted to taking carbonated drinks within the previous 7days and $147(9.5 \%)$ missed breakfast, lunch and supper as single meal. Breakfast only was skipped by $71(4.6 \%)$ while 160 $(10.3 \%)$ took lunch outside the home. The methods used to control weight were eating less food or fats, fasting, use of diet pills, inducing vomiting/use of laxatives.

Skipping meals and taking meals outside the home was significant for the sex, ( $p$ value $<0.05$ ), school setting (p value .000) and the infrequent intake of fruits/ vegetables ( $p$ value .025). Those that skipped meals showed significant stunting (p value .009), while those who took fruits and vegetables infrequently had significant wasting ( $p$ value .049).

Conclusion: poor dietary habits were identified among the adolescent. Malnutrition especially stunting and wasting was identified among those that skipped meals and took little fruits and vegetables.

Key words: dietary habits, adolescent, urban, rural, prevalence, nutritional status, carbonated drinks. 


\section{Introduction}

Healthy eating patterns in childhood and adolescence promote optimal childhood health, growth, and intellectual development; prevent immediate health problems, such as reduced capacity for learning and work. ${ }^{1}$ It may also prevent long-term health problems such as iron deficiency anaemia, obesity, eating disorders, dental caries, coronary heart disease, cancer, and stroke. ${ }^{1}$ Adolescents constitute a significant proportion of the world's population especially in developing countries ${ }^{2,3}$ accounting for $22.1 \%$ of Nigeria's population. ${ }^{4}$ The demographic weight of adolescents and their propensity for risky health behaviours fuels concerns about issues regarding their health coupled with the fact that promoting the health of adolescents today guarantees the health of tomorrow's adult population. Leading causes of morbidity and mortality among adolescents have been linked to the behavioural risks among others that include unhealthy dietary habits. ${ }^{5}$

According to the World Health Organization (WHO), dietary recommendations for individuals and populations should provide adequate energy balance for a healthy weight. Such diet should include a limited intake of fats, while shifting fat consumption away from saturated fats to unsaturated fats and elimination of transfatty acids. It should also include increased consumption of fruits and vegetables, legumes, whole-grains and nuts, while limiting the intake of free sugars and salt (Sodium) consumption. ${ }^{6}$ A poor dietary habit may be described as all dietary behaviours that negate the above -mentioned ideals. Studies in both developed and developing countries have identify some poor dietary habits namely; skipping breakfast, increased intake of high calorie snack, eating outside the home, consumption of soft-drink among adolescents and low consumption of fruits, vegetables and use of supplements. $5,7-10$

Dietary habits and choice of food influences nutrient and energy consumption and are developed over a period especially during adolescence. Nutritional problems among adolescents can arise from the result of dietary inadequacies, principally from poor dietary choices, which may be related to physiologic, socioeconomic and psychological factors, in the presence of additional nutritional demands imposed by growth sprout during adolescence. ${ }^{2}$ A WHO school-based student health survey in Oman that described the pattern of dietary behaviour among adolescents; showed that about 50\% missed breakfast, $33.4 \%$ usually drink sugar-sweetened carbonated soft drinks, $10 \%$ ate fast-foods regularly and $70 \%$ ate fruits and vegetable regularly. ${ }^{11}$ Of these $19.5 \%$ were overweight, while over $30 \%$ were trying to lose weight. $^{11}$ Two studies from south west Nigerian reported that wheat flour based fast foods with sweetened beverages such as carbonated and malted drinks, fruit juice and alcoholic beverages formed snacks eaten among the students. ${ }^{10,12}$ Onyiriuka et $\mathrm{al}^{13}$ reported on weight status and eating habit among 2097 urban adolescent school girls, showed that 1009 (48.1\%) admitted to skipping at least one meal a fortnight. Over half of the participants $(60.2 \%)$ ate fast food at least once a week, with more than three-quarters of them $(76.4 \%)$ consumed fast food along with soft drinks. They reported that the prevalence of both overweight $(24.5 \% \mathrm{v} .13 .2 \%)$ and obesity $(2.5 \%$ v. $1.1 \%)$ were higher among girls who skipped meals compared with their peers who did not skip meals (odds ratio $0.4,95 \%$ CI 0.32 - 0.50). $\mathrm{Adu}$ et $\mathrm{al}^{7}$ reported on nutritional status among Nigerian undergraduate university students showed that about $3 \%$ did not consume fruits at all, while the consumption of vegetables was low among the students. $50 \%$ of them consume vegetables occasionally; $39 \%$ of them, weekly and only $11 \%$ of them daily. About half of the students $(53 \%)$ who participated in the study were overweight, while $6 \%$ and $15 \%$ were obese and underweight respectively.

The null hypothesis for this study is that the pattern of dietary habits is not associated with poor nutritional status among adolescents. Therefore the aim is to determine the dietary eating patterns and associated nutritional status among adolescents in secondary schools within Abuja Municipal area council (AMAC).

\section{Materials and methods \\ Study design and area}

The study was cross-sectional conducted among adolescents in secondary schools in the Abuja Municipal area council of the Federal capital territory of Nigeria.

\section{Sampling technique}

A multistage sampling was employed in this study. All schools in the Abuja Municipal Area council (AMAC) were stratified into urban and rural schools. Eight schools were selected by balloting from a list of schools obtained from the Education center. Four schools were selected from four major districts of AMAC and four from the rural areas, making a total of eight schools.

\section{Sample size determination}

The calculated sample size was based on the Fisher's formula ${ }^{14} \mathrm{~N}=2 \mathrm{z}^{2} \mathrm{pq} / \mathrm{d}^{2}$; where $\mathrm{N}$ is the desired sample size when population was less than 10,000 ; $\mathrm{z}$ at the normal Standard Deviation (SD) set at 1.96 corresponding to $95 \%$ confidence interval $(\mathrm{CI})$ and $\mathrm{p}$, the prevalence; set at $50 \%$ of poor dietary eating habits as no similar report has been done in the study environment. The $\mathrm{q}$ is the proportion 1-p; the degree of accuracy (d) set at $5 \%$ (0.05). Hence, $\mathrm{N}=3.84 * 0.50 * 0.50 /(0.05)^{2}=768.32$; plus a $10 \%$ attrition rate, approximated to 800 .

\section{Study population}

Only students who were confirmed (using school records and/or birth certificate) to be between the ages of 10 and 19 years were selected. Consent/ assent from the 
school authorities and individual subject were obtained before enrolment, while physically challenged adolescents were excluded. Information from the adolescents were obtained using a structured questionnaires administered by principal investigator or a trained assistance.

\section{Methods}

Approval for the study was obtained from the ethics committees of National Hospital Abuja, the Universal Basic Education and the Secondary School Education Boards of the F.C.T. Consent was obtained from the selected schools' principals/administrators, parents as well as the adolescents. The socioeconomic status of the students was determined by a method described by Olusanya et al based on the educational attainment of the mother and father's occupation. ${ }^{15}$

With a structured self designed, pre-tested questionnaire the subject's bio data, dietary habits, knowledge of nutrition and general physical examination were recorded. The dietary assessment questions included intake or missing of breakfast, lunch and dinner; the use of drugs, fasting or induction of vomiting to control weight in the previous 30days; where main meals (breakfast, lunch and dinner) were eaten, at home or outside the home; the daily use of carbonated / sweetened drinks within the previous seven days to interview; the eating of fruits and vegetables at least five times within the previous seven days to interview and the frequency of snacking by the subjects. Dietary knowledge and preference was assessed as to what constituted a balanced diet with examples; and subject's favorite food and what informed their choices such as taste, balanced diet, satisfying, and cost. The subjects answered yes, no or do not know to the questions. Subject's height and weight was taken in the presence of a chaperon assigned by the school. The floor-type height $(\mathrm{H})$ and weight $(\mathrm{W})$ measuring scale model ZT-120 were obtained. The nutritional status was determined using the formula: Body mass index (BMI) $=\mathrm{W} / \mathrm{H}^{2}$, where $\mathrm{W}=$ weight (in kilograms) and $\mathrm{H}=$ height (in meters), to the nearest $0.1 \mathrm{~kg}$, for weight and $0.1 \mathrm{~cm}$ for height. The age and sex specific height and BMI percentile for each subject was determined using the 2007 WHO Height and BMI growth charts for age 5-19years. ${ }^{16}$

The students were then classified into one of the following categories based on the percentile of their BMI on the age-and-sex-specific WHO growth chart as follows: wasted (below $3^{\text {rd }}$ percentile), normal $\left(3^{\text {rd }}\right.$ to $84^{\text {th }}$ percentile), overweight $\left(85^{\text {th }}\right.$ to $96^{\text {th }}$ percentile) and obese (at least $97^{\text {th }}$ percentile). Also, they were classified, based on the WHO sex-and-age-specific height growth chart, as stunted (below $3^{\text {rd }}$ percentile) and normal (3rd percentile and above). ${ }^{16}$

Data was analysed using Statistical package for social sciences (SPSS), version 17. Categorical data were expressed as rates, proportion and percentages while continuous variables were expressed as means, standard deviation and ranges. Association between categorical variables were evaluated using Chi square $\left(\chi^{2}\right)$ statistics.
Test results were considered as significant if $p$-value was $<0.05$. Factors found to be significant in the bivariate analysis were subjected to logistic regression analysis to identify effect modification and control for confounding.

\section{Results}

A total number of 1,700 students were enrolled, 850 each from both the four urban schools and rural schools respectively. $1550(91.2 \%)$ questionnaires were analyzed due to withdrawal of consent in $150(8.8 \%)$.

Seven hundred and eighty $(50.3 \%)$ of the students were from urban schools while $770(49.7 \%)$ were from rural schools. There were $688(44.4 \%)$ males and 862 $(55.6 \%)$ females, giving a male: female of $1: 1.3$. The mean age of the study population was $14.43 \pm 1.94$ years. The students in early adolescence (10-13 years) were $500(32.3 \%)$; middle adolescence (14-16 years), 818 $(52.8 \%)$ and late adolescents, $232(15.0 \%)$.

The ethnic groups of the students' population were Igbos $460(29.7 \%)$, Yorubas 305

(19.7\%), Hausas 102 (6.6\%) and others (Gbagis, Nupes, Ebiras and Fulanis) 682 (44\%). The upper social class constitutes $708(45.7 \%)$ of the study population; 542 $(35.0 \%)$ middle class and $300(19.3 \%)$ in the lower class. Of the 780 from urban areas $502(64.4 \%)$ belong to the upper class and $68(8.7 \%)$ to the lower class. In the rural area $206(26.8 \%)$ and $232(30.1 \%)$ belong in upper and lower class respectively. These difference was statistically significant $\mathrm{p}=.000$.

Of the 1550 adolescents, various categories of malnutrition were seen namely; overweight $195(12.6 \%)$, stunting 174(11.2\%), obesity $43(2.8 \%)$ and wasting $27(1.7 \%)$.

Food preferences were based on taste good in 546 (35.2\%), balanced diet 530(34.2\%), satisfying 242 $(15.6 \%)$ and don't know 232(15\%). Five hundred and thirty nine $(34.8 \%)$ had good nutritional knowledge of a balanced diet.

Five hundred and forty six (35.2\%) of the student admitted to taking carbonated drinks within the previous 7 days to interview, while the remaining 1004 (64.8\%) admitted to not taking any carbonated drinks within the same period.

\section{Dietary patterns and influencing factors}

There were several categories of combinations of missed meals, only $147(9.5 \%)$ had a single form, missing either breakfast, lunch and supper.

Breakfast, lunch and supper were skipped by $71(4.6 \%)$, $59(3.8 \%)$ and $17(1.1 \%)$ respectively and when lunch was taken, $160(10.3 \%)$ was taken outside the home, while supper was the least meal taken outside the home, $7(0.5 \%)$ illustrated in table 1. 


\begin{tabular}{lcccc}
\hline \multicolumn{4}{l}{ Table 1: } & \multicolumn{4}{l}{ Pattern of main meals in the study population } \\
Meals & $\begin{array}{c}\text { Taken at } \\
\text { home }\end{array}$ & $\begin{array}{c}\text { Taken outside } \\
\text { the home }\end{array}$ & Missed & Total \\
& No $(\%)$ & No $(\%)$ & No (\%) & No (\%) \\
\hline Breakfast & $1388(89.5)$ & $91(5.9)$ & $71(4.6)$ & $550(100.0)$ \\
Lunch & $1331(85.9)$ & $160(10.3)$ & $59(3.8)$ & $1550(100.0)$ \\
Supper & $1526(98.5)$ & $7(0.5)$ & $17(1.1)$ & $1550(100.0)$ \\
\hline
\end{tabular}

Table 2 show that some of the dietary habits and methods adopted by the adolescents to control weight. Some of the poor dietary habits were skipping meals 147 $(9.5 \%)$, p value 0.000 ; eating outside the home, 258 $(16.6 \%), \mathrm{p}$ value 0.019 ; infrequent intake fruits and vegetables, 502(32.4\%), p value 0.025 . The methods used to avoid weight gain or lose weight were eating less food or fats, fasting, use of diet pills, inducing vomiting/use of laxatives.

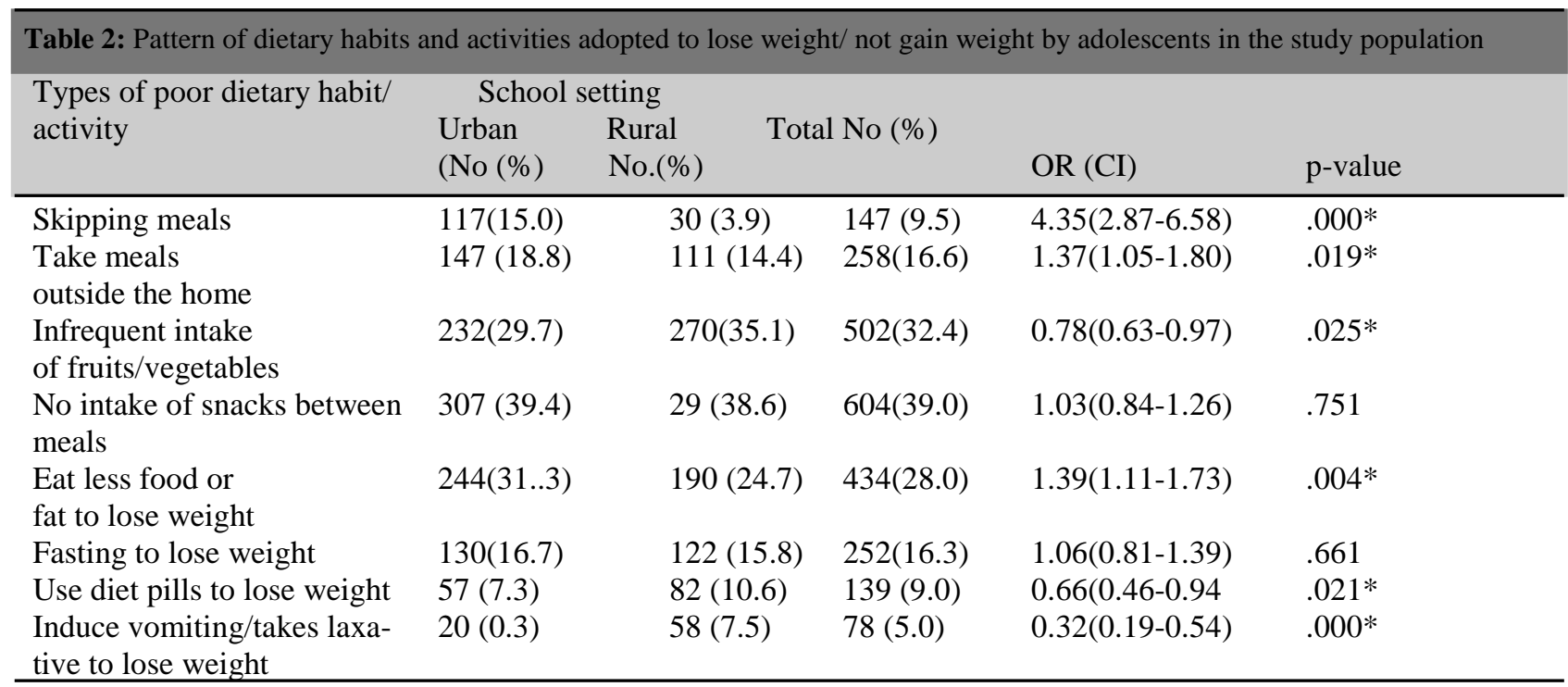

Total urban- 780 , total rural -770

Fig 1: The relationship between dietary eating habits and adolescent developmental stages.

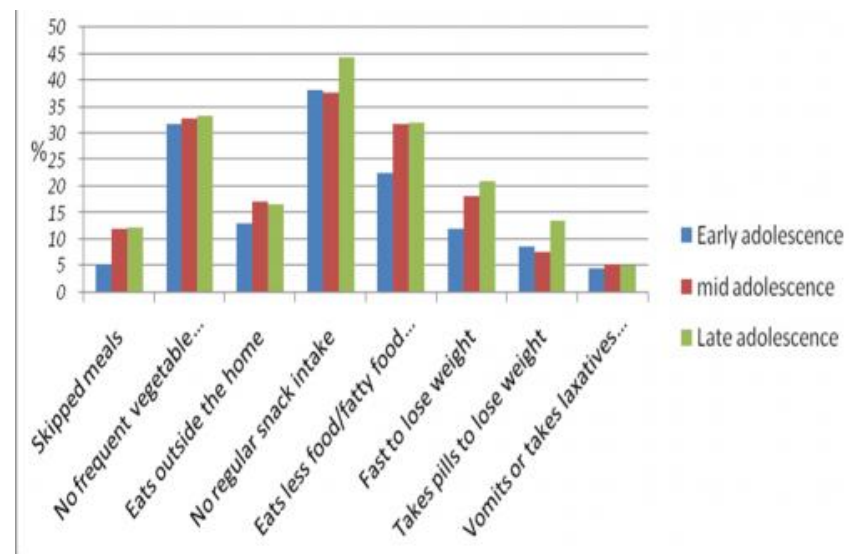

Among the mid and late adolescents over $30 \%$ reported no regular snacks, no frequent fruits/ vegetables and eating less food/fat, while the younger early adolescences had the least skipping of meals and use of vomiting/ laxatives to control weight gain as shown in figure 1 .
Table 3 show that skipping meals and taking meals outside the home was significant for the sex in favour of the females, $\mathrm{p}$ value .013 and $\mathrm{p}$ value .012 respectively; school setting show that skipping meals was significant in favour of urban area ( $p$ value .000) while the infrequent intake of fruits/ vegetables was significant in favour of rural area ( $\mathrm{p}$ value .025). The working mother's child was significantly more likely not to take snacks between meals or eat fruits/ vegetable, ( $\mathrm{p}$ value .001 , OR 1.5 and .020 , OR 1.35) respectively. Also students from higher social class were significantly more likely to not take snacks between meals, ( $\mathrm{p}$ value .004, OR 10.93) and not take fruits/ vegetables ( $\mathrm{p}$ value .001, OR 14.29). 


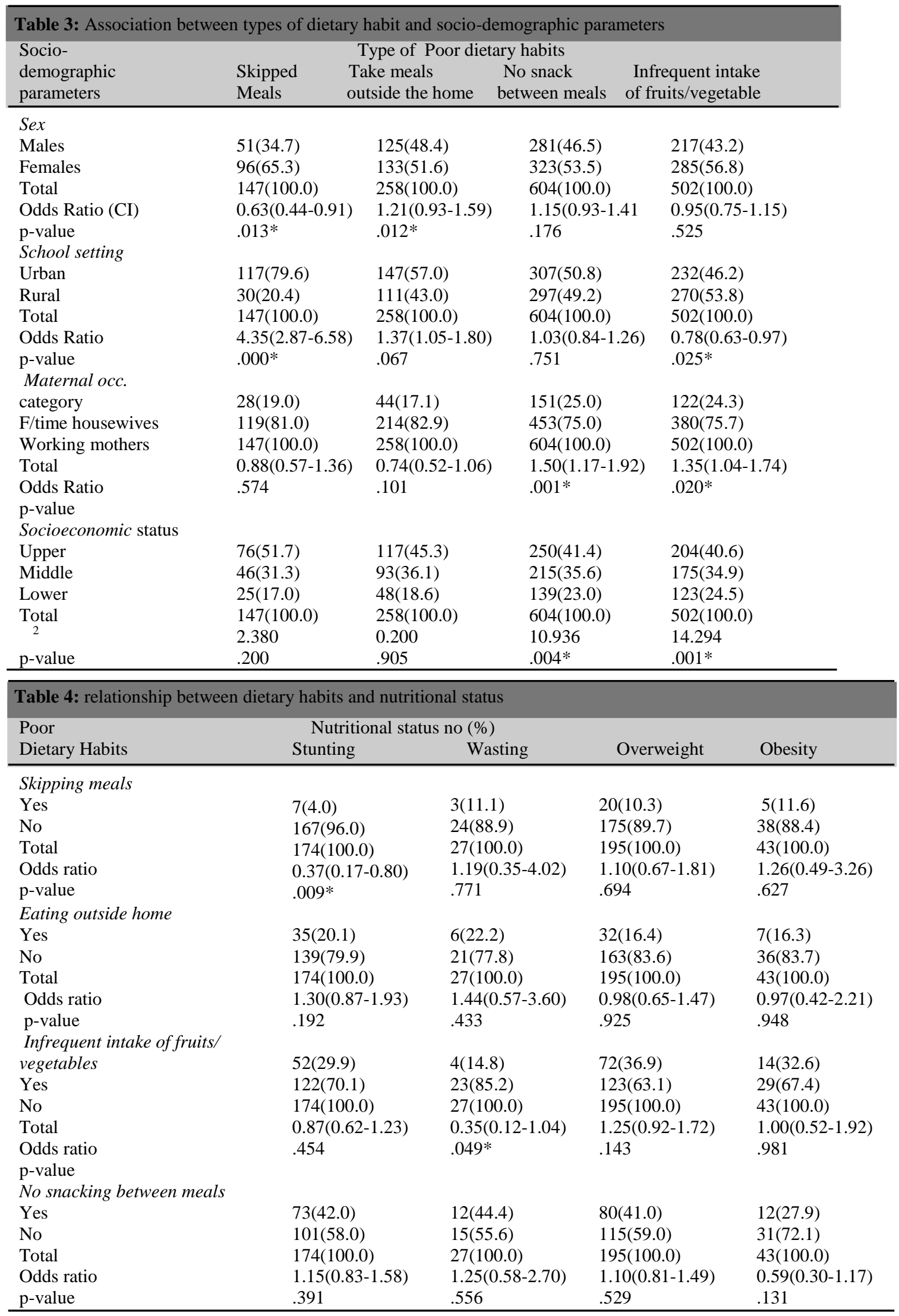

Table 4 shows that stunting was significant in the group that skipped meals, ( $p$ value .009), and wasting among those whose intake of fruits and vegetables was infrequent, ( $\mathrm{p}$ value .049).

\section{Discussion}

Several forms of poor dietary habits were observed among the adolescents in the present study. The skipping of main meals was prevalent in $9.5 \%$ and the most 
frequently skipped meal was breakfast in $4.6 \%$ of the adolescent population. This prevalence of skipping breakfast is much lower compared to $50 \%$ and $80 \%$ reported among adolescent students in Oman and the kingdom of Saudi-Arabia respectively. ${ }^{11,17}$ Reasons for missing breakfast were not explored in this report. However, in the report by Onyiriuka et al ${ }^{13}$, some of the reasons given for skipping breakfast are lack of appetite in the morning, lack of time, no easily prepared food, self perceived overweight and religious reasons. Skipping of breakfast has been shown to adversely affect children's performance in problem-solving tasks. ${ }^{18}$ A study among low-income elementary school students indicated that those who participated in the school breakfast program had greater improvements in standardized test scores and reduced rates of absenteeism and tiredness compared to children who qualified for the program but did not participate in the school breakfast program. ${ }^{19}$ Other dietary habit observed in the present report were taking meals outside the home, infrequent intake of fruits and vegetables and snacking. These have been similarly documented, namely: eating out of the home and skipping meals. ${ }^{5}$ Breakfast is the most commonly missed meal by adolescents leading to higher probability of snacking during the day. ${ }^{5}$ The latter may involve eating nutritious and/or junk foods; ${ }^{5}$ binge eating and starvation. ${ }^{6}$ The detrimental consequence of poor dietary habits such as skipping breakfast has been reported by Pollitt et $\mathrm{al}^{18}$ and Meyers et $\mathrm{al}^{19}$ and these include increasing prevalence of poor academic performance on standardized tests, absenteeism and tiredness among those who skipped breakfast when compared with those who always ate breakfast.

Factors affecting food choices among adolescents in the present study included taste, balanced diet and satisfying. Studies have shown similar factors that influence food choices and preferences, mainly the greater quest for independence, taste, quality of food, food availability, cost, general knowledge of nutrition, socioeconomic status, parental and peer influence, maternal nutritional knowledge, exposure to food advertisement, age and sex and culture-specific dietary practices. ${ }^{2}$

This report shows that some of the adolescents did not take snacks, and / or ate fruits and vegetables frequently. A snack meal consumed in addition to the three regular meals in a day is expected to improve the adolescents' growth and meet their developmental requirements. However, snack meals can be inadequate in calorie contents. The report by Afolabi et $\mathrm{al}^{10}$ showed that $100 \%$ of the students studied patronized fast foods made from wheat flour taken with sweetened beverages such as carbonated and malted drinks, fruit juice and alcoholic beverages. The WHO survey among Oman adolescents also reported that some foods that were used for snacks included carbonated drinks $(33.4 \%)$ and fast foods $(10 \%)$, which mostly are purchased outside the home. ${ }^{11}$ This practice of snacks use is becoming more common in societies due to westernization, and especially among those who spend long hours outside the home. Fruits and vegetable intake was infrequent for both sexes in the present study report, which may be related to the higher cost of such food products despite their value to provide micronutrients as free radical scavengers for the body. They also contain fibers that help with digestion and weight control. This low intake of fruits and vegetables is similar to other reports. . $^{-9,11,13}$

The present study showed that mid and late-adolescents had the highest prevalence of poor dietary habits compared to those in the early-adolescencece. Adolescents in their mid-developmental stage have been shown to have a higher tendency to engage in poor dietary habits due to their relatively higher vulnerability to risk-taking, ${ }^{20}$ while those in the late-adolescence stage engaged in poor dietary habits in their greater quest for independence and reduced parental influence. Other eating practices in the present study were eating less food or fat, fasting, taking diet pills or laxatives and by inducing vomiting. These practices were adopted to weight-losing or prevent weight gain have been reported among adolescents in the United states and worldwide. ${ }^{1,21}$ Possible reasons for some of these practices are the influence from exposure to media adverts, ${ }^{2}$ psychological factors such as search for identity, pursuit of independence and body image concerns among adolescents. ${ }^{2}$ The deliberate restriction of food intake over long periods can lead to poor growth and delayed sexual development. $^{22}$ Harmful weight loss practices have been reported among girls as young as 9 years old. ${ }^{23}$

A report showed that among the 8th- and 10th-grade students, $32 \%$ skipped meals, $22 \%$ did fast, $7 \%$ used diet pills, 5\% induced vomiting after meals, and 3\% used laxatives to lose weight. ${ }^{24}$ Adolescents should be educated about the dangers of unsafe weight-loss methods and about safe ways to maintain a healthy weight. This report showed that more females skipped meals compared to males, which may be related their greater desire to attain and maintain a slim body image. However more males were reported to eat outside the homes than females, which could be due to the more outgoing nature of the adolescent male. Eating disorders often start in adolescence, and greater than $90 \%$ of cases occur among females. ${ }^{25}$ Reports have shown that compared with adolescents who have normal eating patterns, adolescents who have poor eating habits tend to have lower selfesteem; a negative body image; and feelings of inadequacy, anxiety, social dysfunction, depression, and moodiness. ${ }^{26}$ Eating disorders can cause many severe complications, and mortality rates for these disorders are among the highest for any psychiatric disorder. ${ }^{26,27}$

This report show that urban school adolescents skipped meals more than the rural resident, in contrast to the report by Olumakaiye et al where a higher proportion of adolescents who ate three meals daily were domiciled in rural areas. ${ }^{12}$ Rural adolescent took less fruits and vegetable frequently compared to the urban adolescents, which could be due to a greater awareness of the values of fruits and vegetables by the urban adolescent, and the probable ignorance and / or inability to afford them by the rural adolescent. The expectation would have been 
that the rural dwelling adolescent should have access to fresh fruits and vegetables from farm products, but may have poor intake due to the practice of farming principally for commercial purposes in such setting. ${ }^{21}$ Maternal occupation was significantly related to lack of snacks between meals and infrequent intake of fruits and vegetables. The educational level of the mother has been shown to greatly influence the family health and socioeconomic status, especially where the mother is gainfully employed to help contribute to the family needs. Higher maternal education may enhance the awareness of the significance of taking three main meals which will reduce snacking, and the need for fruits/vegetables for adequacy of diet that meet the need of growing adolescents. This study showed that adolescents whose mothers were full time house wives compared to working mothers skipped meals less, took meals outside home more, had no snacks between meals and took more of fruits and vegetables. The reasons for these finding could be variable, which may include affordability, family food and cultural values, influence of adverts and education or simply indifference. The high rate of infrequent snacking between meals cuts through all the socio economic classes along with infrequent intake of fruits and vegetable among the adolescents. Social class has been known to influences human behaviour in areas of food choices, number and types of meals taken, including the use of snacks and the quality and quantity of diets available to adolescents. ${ }^{1}$

Various forms of malnutrition have been associated with adolescents' dietary habits that may predispose to chronic non-communicable diseases like overweight and obesity, diabetes mellitus and coronary heart disease. ${ }^{17}$ This study show that stunting was significantly higher among adolescents who skipped their meals. Stunting has been associated with prolonged undernourishment among many other reasons. Also, wasting was found to be higher among adolescents who did not frequently ingest fruits/vegetables. Wasting is a condition associ- ated with drastic reduced food intake and severe illnesses. Malnutrition worldwide have long been associated with inadequate intake, insufficient or inappropriate food ingestion, wrong food choices and cultural practices.

\begin{abstract}
Conclusion
The adolescent were identified to have poor dietary habit, which included meal skipping, eating outside the home and infrequent intake of fruits and vegetables. Malnutrition was significant among those that skipped meals with infrequent intake of fruits and vegetables. These dietary habits and food choices might have influenced the optimal growth and development even for the adolescent. Education on healthy life style habits will contribute to improved adolescent health.
\end{abstract}

\section{Conflict of interest: None \\ Funding: None}

\section{Limitation}

Content of snacks could not be verified or analyzed for nutritional contents and value.

\section{Acknowledgement}

Our gratitude go to the adolescents, their parents and the management of the various schools in this study, the managements of the Universal Basic Education and Senior secondary school education boards of the Federal capital territory.

\section{References}

1. Guidelines for School Health Programs to Promote Lifelong Healthy Eating CDC. 1996. www.cdc.gov/mmwr/preview/ mmwrhtml/00042446.htm

2. World Health Organization discussion paper on Adolescent Nutrition 2005: Nutrition in adolescence: Issues and Challenges for the Health sector: Issues in Adolescent Health and Development [online]. 2005. Accessed: 7/7/11. Available from: URL:http:// www.who.int/child-adolescenthealth/New_Publications/ ADH/ ISBN_92_4_159366_0_pdf.
3. United Nations Food and Population Agency: State of the World Population [online].2005. Accessed: 4/7/11. Available from: URL:http://www.unfpa.org/ swp/2005/english/ch5/chap5

4. Federal Republic of Nigeria official gazette; Publication of 2006 National census; 2007.

5. Youth Risk Behaviour Surveillance System [online]. 2013 [cited 2013 Sept 13]. Available from: URL:http:// www.cdc.gov/healthyouth/ yrbs/index.htm.
6. World Health Organization. Child and adolescent health and development. Adolescent nutrition[online], 2000-2004. URL: http://www.who.int/ child-adolescent-health/ nut.htm. [cited 2012 February 13]

7. Adu OB, Falade AM, Nwalutu EJ, Elemo BO and Magbagbeola OA. Nutritional status of undergraduates in a Nigerian university in southwest Nigeria. International Journal of Medicine and Medical Sciences 2009, Vol. 1 (8), pp. 318-324. 
8. Sarkar M, Manna N, Dr. Sinha S, Sarkar S, Pradhan U. Eating habits and nutritional status among adolescent school girls: an experience from rural area of West Bengal. OSR Journal of Dental and Medical Sciences (IOSR-JDMS) 2015; 14: 5460.

9. Abdelaziz SB, Labib Youssef MR, Sedrak AS, Labib JR. Nutritional Status and Dietary Habits of School children in Beni-Suef Governorate, Egypt. Food and Nutrition Sciences 2015; 6: 54-63.

10. Afolabi, WAO, Towobola, SK, Oguntona, CRB and Olayiwola IO. Pattern of fast foods consumption and contribution to nutrient intake of Nigerian university students. Int J Educ and Research 2013; 1 (5).

11. Oman Global school-based student health survey [online]. Available from:URL: http:// www.who.int/chp/gshs/ oman_GSHS_countryreport.pdf. 2005. [cited 2013 Oct 12].

12. Olumakaiye MF, Atinmo Tola, Olubayo-Fatiregun MA. Food consumption patterns of Nigerian adolescents and effects on body weight. $J$ Nutr Educ and behaviour 2010; 42 (3):144151.

13. Onyiriuka AN, Umoru DD, Ibeawuchi AN. Weight status and eating habits of adolescent Nigerian urban secondary school girls. S Afr J child health 2013; 7 (3) : $108-112$.

14. Araoye MO. Subject selection. In: Research methodology with statistics for health and social sciences, Nathadex (Publishers) 2004; 115-29.
15. Olusanya O, Okpere E, Ezimokhai M. The importance of social class in voluntary fertility control in a developing country. West Afr J Med 1985; 4:205-12.

16. World Health Organization Child Growth Standards [online]. 2006. Accessed 1/7/08. Available from: URL:http://www.who.int/ entity/childgrowth/standards/ en.

17. Amin TT, Al-Sultan AI, and Ali A.. Overweight and obesity and their association with dietary habits and sociodemographic characteristics among male primary school children in Al-Hassa, Kingdom of Saudi Arabia. Indian J Community Med 2008; 33(3): 172 - 181.

18. Pollitt E, Leibel RL, Greenfield D. Brief fasting, stress, and cognition in children. Am J Clin Nutr 1981; 34:1526-33.

19. Meyers AF, Sampson AE, Weitzman M, Rogers BL, Kayne H. School Breakfast Program and school performance. Am J Dis Child 1989; 143: 1234-9.

20. Steinberg L. Risk-taking in adolescence; New perspectives from brain and behavioural science. Curr directions in psychol sci 2007;16 (2): 55-59.

21. Hoffman K, Bryl W, Marcinkowski JT, Rzesos A, Wgtyla E, Pupek-Musialik D. Dietary behaviours of adolescents from rural and urban areas in the district of Szamituly. Ann Agric and Eviron med 2012; (19): 103-107.
22. Lifshitz F, Moses N. Nutritional dwarfing: growth, dieting, and fear of obesity. $J A m$ Coll Nutr 1988; 7(5):367-76.

23. Maloney MJ, McGuire J, Daniels SR, Specker B. Dieting behaviour and eating attitudes in children. Pediatrics 1989; 84(3):482-9.

24. American School Health Association, Association for the Advancement of Health Education, and the Society for Public Health Education. The National Adolescent Student Health Survey: a report on the health of America's youth. Oakland, CA: Third Party Publishing, 1989.

25. American Psychiatric Association Task Force on DSM-IV. Diagnostic and statistical manual of mental disorders: DSMIV. Washington, DC: American Psychiatric Association, 1994.

26. Herzog DB, Copeland PM. Eating disorders. $N$ Engl J Med 1985; 313(5):295-303.

27. Trowbridge F, Collins B. Measuring dietary behaviours among adolescents. Public Health Rep 1993; 108(suppl 1):37-41. 